\title{
Biopolítica, Formas de Controle Sobre a Vida e a Deficiência: OlHares OUTROS SObre A INCLUSÃO E A RESISTÊNCIA NA ESCOLA
}

\author{
Pedro Angelo Pagni ${ }^{1}$ \\ Universidade Estadual Paulista Júlio de Mesquita Filho - UNESP \\ Divino José da Silva ${ }^{2}$ \\ Universidade Estadual Paulista Júlio de Mesquita Filho - UNESP \\ Alexandre Filordi de Carvalho ${ }^{3}$ \\ Universidade Federal de São Paulo - UNIFESP
}

A educação, não obstante as promessas formativas e emancipatórias que postulou, se constituiu em das artes de governo sobre a infância, ao se instituir na escola e compreender em um conjunto de dispositivos destinados a ampliar as formas de controle sobre a vida. Estas formas específicas de controle da vida produzidas pela instituição escolar se legitimam por tecnologias e saberes que as justificam em torno de um paradigma de sujeito e de normalidade. Na atualidade, quando o sujeito se restringe ao cerebral e a norma passa a legitimar as políticas de inclusão dos diferentes modos de existência, parece-nos que as promessas formativas e emancipatórias caem por terra, restringindo a educação a uma tecnologia do biopoder com funções bastante específicas, sobretudo, em relação aos designatos deficientes. Diagnosticar tais especificidades é o propósito geral deste dossiê que parte do empreendedorismo de si, centrado na figura do sujeito cerebral como paradigma da biopolítica atual, para apresentar algumas possíveis ontologias do devir deficiente, os modos de existência assim designados e as práticas que os tomam eticamente como uma expressão da resistência às formas excessivas de controle da vida estabelecidas na escola.

Interessa-nos, com o conjunto de artigos apresentados neste dossiê, problematizar os dispositivos de biopoder da escola e a formação do empreendedor de si ao qual tem se destinado na atualidade, como parte das estratégias do investimento educacional do neoliberalismo. Nessa problematização, os artigos e a entrevista procuram demonstrar a articulação de

\footnotetext{
${ }^{1}$ E-mail: pagni@terra.com.br

2 E-mail: divino.js21@uol.com.br

${ }^{3}$ E-mail: afilordi@gmail.com
} 
biopolítica, formas de controle sobre a vida e deficiência: olhares outros sobre a inclusão e a resistência na escola

alguns desses dispositivos com as políticas de inclusão, com o propósito de analisar o quanto a deficiência é produzida socialmente e a possibilidade de a sua emergência nas relações intersubjetivas indicarem a presença de outras práticas, assim como darem visibilidade aos processos de subjetivação outros existentes na escola. Interpelamo-nos, de um modo geral, até que ponto a problematização dos dispositivos do biopoder e a emergência do pensar na deficiência como um modo de existência na escola podem se constituir num campo fecundo de interlocução para a Filosofia da Educação e para o ensino de Filosofia. Para tanto, nos perguntamos em que medida a problematização de uma pedagogia que se centra na neuroeducação, e cada vez mais nas suas teorias, apenas endoçariam a redução do sujeito às redes neurais, inaugurando, assim, um campo mais problemático para a subtração da vida e para certa repartição entre os normais e anormais. Tal pedagogia, embora supostamente mais objetiva, traz em si uma maior instrumentalidade ao ensino escolar, restringindo-o a fins cada vez mais concernentes ao empreendedorismo de si.

Indagamos também se essa variante interpretativa não pode consagrar a fórmula de algumas políticas públicas que, esboçadas desde os anos 1970, se apoiam em evitar a deficiência para programar a eficiência no sentido de eleger este último como princípio moral da ação humana em todos os campos da vida e aquela como centro de uma biopolítica atual, ao mesmo tempo em que ponderamos sobre uma ontologia capaz de tornar positiva o devir-deficiente na escola, dando visibilidade ao sentido ético-formativo que as relações com ele produzem.

No primeiro artigo, intitulado Biopolítica e os processos de cerebralização da vida e da educação, Divino José da Silva (UNESP/Presidente Prudente) e Alexandre Fernandez Vaz (UFSC) apresentam um diagnóstico sobre a restrição do sujeito ético ao sujeito cerebral, seguindo as interpretações de Francisco Ortega e estendendo-a ao recente aparecimento das neurociências na educação, problematizando o significado deste aparecimento e os efeitos daquela restrição para o cenário biopolítico atual. Frente a tal cenário, podemos problematizar o 
lema das políticas públicas de que a deficiência deveria ser evitada para se priorizar a programação da eficiência como imperativo moral a formar o sujeito e o delineamento de um paradigma político, que poderiam ser afrontados a partir de um olhar que concebe a deficiência como um modo de existência e que a pensa à luz de uma ontologia que, ao tomá-la como algo positivo, dentre outros efeitos, possibilita a sua visibilidade na escola.

Essa ontologia da deficiência é explorada no dossiê em quatro direções distintas. Duas delas convergem ao adotarem a noção de plasticidade destrutiva e a perspectiva da ontologia do acidente de Catherine Malabou para discutir a deficiência como constitutiva da formação humana. Uma delas, chega a presentar um novo gênero por assim dizer de antropotécnica e, portanto, de formação capaz de interpelar as antropologias nas quais se fundamentam a pedagogia, nos termos apresentados por Alexandre Simão de Freitas (UFPE) no artigo O devir-deficiente da pedagogia: notas para uma antropologia filosófico-educacional em torno da plasticidade. A outra concebe a deficiência como algo constitutivo de nosso ser proteico, como uma força destrutiva com a qual nos havemos enquanto humanos, tal como nos apresenta Andréa Díaz Genis (Universidad de la República del Uruguay) no ensaio Formación humana y fuerza plástica. La diferencia que nos constituye. Por sua vez, ao elaborar um Esboço para um pensamento da diferença e do devir deficiente na educação, Rodrigo Barbosa Lópes (UNESP/Pres. Prudente) recobra parcialmente as teses anteriores à luz de filósofos da diferença como Gilles Deleuze e Michel Foucault para desafiar a pedagogía e a filosofia da educação a reverterem seu platonismo, a se voltarem às práticas e aos devires emergentes na escola, dentre os quais, o devir deficiente, propondo-se a analisá-lo particularmente como um acontecimento e indicando um terceiro caminho teórico para auxiliar na sua reflexão. Por fim, a quarta direção acerca da ontologia da deficiência é explorada por Blanca Estela Zardel Jacobo Cúpich (UNAM/UIICSE/FES/Iztacala/México), no artigo La constitución o producción de la subjetividad, del sujeto desde el psicoanálisis y del sujeto sujetado al discurso de la "discapacidad", que analisa o lugar da deficiência na constituições do sujeito à luz da psicanálise e de interlocuções com Heidegger e Levinas, indicando uma fragilidade psíquica substancial da qual somos 
biopolítica, formas de controle sobre a vida e deficiência: olhares outros sobre a inclusão e a resistência na escola

constitutivos e que se revela no jogo de espelhos com esse outro significado socialmente como deficiente.

Essa consonância de direções e de vozes, embora cheia de contrapontos e fugas entre si, se harmonizam em torno da deficiência como algo que nos constitui e nos forma como sujeitos, como humanos. Se harmonizam também em torno do incomodo que provoca a presença desse outro, tão estranho e familiar, chamado de "deficiente", particularmente, em práticas como aquelas que circulam em instituições como a escola e que muitas vezes se tecem em redes com outros devires e outras diferenças em nossa sociedade, agenciando uma espécie de agir político subterrâneo, invisível por assim dizer. Com vistas a tornar visível o devir deficiência e as suas formas de vida comuns, Pedro Angelo Pagni (UNESP/Marília) os retrata a partir da estética da existência foucaultiana, no ensaio Ética da amizade e deficiência: outras formas de convívio com o devir deficiente na escola, defendendo a importância dessa visibilidade para interpelar as atuais políticas de inclusão escolar e para indicar os acontecimentos emergentes com esses modos de exitir outros, assentados na amizade e na confiança, capazes de resistir as tecnologias de biopoder dominantes nessa instituição. Se este último traz uma teorização sobre os modos de existência deficientes, o ensaio El lenguaje de la norma y los individuos frágiles de Carlos Skliar (FLACSO/Argentina) adensa o sentido comum desse devir, reelaborando-o a partir de uma teoria da fragilidade e da debilidade humana, conferindo-lhe um tom literário-filosófico e uma amplitude que escapa à sua tradutibilidade e normalização linguística, abrindo espaço para suas vozes e gestos.

Corroboram essa expectativa de ouvir as vozes e os pensamentos desses modos de vida deficientes os dois últimos artigos deste dossiê. Um deles, de Alexandre Filordi de Carvalho (UNIFESP) e Vanessa Regina de Oliveira Martins (UFSCar), intitulado A anunciação e a insurreição da diferença surda: contra-ações na biopolítica da educação bilíngue, parte da filosofia da diferença para apresentar a voz surda e o seu movimento de resistência à linguagem ostensiva em circulação na escola. O outro artigo, de Chéma Sanchez (Generalitat Valenciana, Espanha), 
intitulada Escuela de Pensamiento Libre. Un viaje desde el estigma de la subnormalidad hasta el empoderamiento de personas entre personas, relata o nascimento de uma experiência de ensino de Filosofia com adultos com alguma deficiência intelectual e com demais pessoas e as linhas gerais de seu desenvolvimento no sentido de mostrar como o pensar livre, inspirado em Lipman, tem auxiliado a promover a inclusão desses deficientes via seu empoderamento e de sua disposição de tomar a palavra. De um lado, são os surdos que se insurgem com sua língua de sinais e com seus signos comuns, assumindo seu lugar de enunciação ou, seria melhor falar, de expressão na escola; de outro, são os deficientes intelectuais que pensam em espaços que ultrapassam essa instituição, mostrando que é possível pensar filosoficamente desde um corpo debilitado, por assim dizer.

Vozes surdas que não precisam ser intermediadas por nenhuma língua que todos entendam, porque estão lá e emergem de uma comunidade que se mostra para quem quiser ver. Pensamentos que não necessitam de um intelectual para falar sobre eles, porque se expõem por si mesmos, evocando um devir comum, outro, inquieto, porque a nossa inteligência não as entende e a nossa racionalidade não os alcança, em virtude de uma deficiência que não é desse outro, mas nossa. Evocação de fragilidades comuns, de amizades possíveis com esse outro chamado deficiente, porque diferente de nós e porque assim foi acordado linguística e socialmente. Visibilidade de insurreições que implodem o edifício normalizador da escola, afrontam as tecnolocias de biopoder vigentes e o princípio de uma racionalidade do desempenho na medida em que a deficiência de cada qual e de qualquer um não suporta mais o imperativo da eficiência, que rege a biopolítica neoliberal, buscando respostas numa ontologia da deficiência e numa ética da diferença ou numa teoria da fragilidade, em vários aspectos próximos às várias designações de infância e de sua reflexão filosófica, retratadas nas páginas da Childhood E Philosophy.

Estes foram os motivos de os organizadores publicarem o dossiê Biopolítica, formas de controle sobre a vida e deficiência: olhares outros sobre a inclusão e a resistência na escola nesta revista, a quem agradecemos pela acolhida de nossa proposta. Aproveitamos também para convidar seus leitores a discutirem conosco os 
biopolítica, formas de controle sobre a vida e deficiência: olhares outros sobre a inclusão e a resistência na escola

desafios dessas formas particulares do devir-deficiente na escola, vistas em sua positividade e em sua diferença, como uma ação política que, transversalmente ao tempo e ao espaço institucional, abre outros campos de reflexão, de engajamento e, por que não dizer, de luta.

Recebido em: 22.08.2016

Aprovado em: 26.08 .2016 